\title{
A c-Met Inhibitor Suppresses Osteosarcoma Progression via the ERKI/2 Pathway in Human Osteosarcoma Cells
}

\author{
Weijie Chen ${ }^{1-3, *}$ \\ $\mathrm{Su} \mathrm{Wu}^{4, *}$ \\ Yang Huang ${ }^{3, *}$ \\ Tingting Zhang ${ }^{5}$ \\ Hao Dong ${ }^{6}$ \\ Xing Zheng ${ }^{3}$ \\ Tao Chen ${ }^{3}$ \\ Xiaokang Gong ${ }^{3}$ \\ Gang Liu ${ }^{1,2}$ \\ Xing Zhao (D) ${ }^{\prime}$
}

'Department of Orthopaedic Surgery, Sir Run Run Shaw Hospital, Zhejiang University School of Medicine, HangZhou, People's Republic of China;

${ }^{2}$ Key Laboratory of Musculoskeletal System Degeneration and Regeneration Translational Research of Zhejiang Province, HangZhou, People's Republic of China; ${ }^{3}$ Department of Orthopedics, Taizhou Municipal Hospital, Taizhou, People's Republic of China; ${ }^{4}$ Department of Orthopedics, The Third People's Hospital of JingDeZhen, JingDeZhen, People's Republic of China; ${ }^{5}$ Taizhou Public Security Supervision Hospital, Taizhou Municipal Hospital, Taizhou, People's Republic of China; ${ }^{6}$ Department of Gastrointestinal Surgery, Taizhou Municipal Hospital, Taizhou, People's Republic of China

*These authors contributed equally to this work

Correspondence: Xing Zhao

Email zhaox@zju.edu.cn

Gang Liu

Email gimmyliugang@zju.edu.cn
Introduction: Osteosarcoma is the most common primary malignancy of the bone among adolescents and children. Despite intensive chemotherapy and aggressive surgery, the 5-year survival rate of osteosarcoma still falls under $70 \%$, mainly due to its tendency to metastasize and to develop drug resistance. Therefore, new treatments for osteosarcoma are urgently needed. HGF/c-Met signaling pathway, when dysregulated, is involved in the onset, progression and metastasis of various cancers, making the HGF/c-Met axis a promising therapeutic target.

Methods: In this study, we found Met to be a cancer-promoting gene in osteosarcoma as well, and aimed to investigate the role of a c-met inhibitor (PHA-665752) in osteosarcoma. For this purpose, two human osteosarcoma cell lines (143B and U2OS) were introduced in this study and treated with PHA-665752. CCK8 cell proliferation assay was performed to obtain the $\mathrm{IC}_{50}$ value of PHA-665752 for $143 \mathrm{~B}$ and U2OS. After that, colony formation assay, transwell migration and invasion assay and wound-healing assay were performed. Furthermore, a tumor-transplanted mouse model was used for in vivo experiments.

Results: Our results showed that PHA-665752 could suppress osteosarcoma progression, promote apoptosis and inhibit proliferation of human osteosarcoma cells. Moreover, we found ERK1/2 pathway to be an important mediator underlying the osteosarcomasuppressing function of PHA-665752. LY3214996, a highly selective inhibitor of the ERK1/2 pathway, was able to antagonize the effects of PHA-665752 in osteosarcoma. Finally, in vivo experiments indicated that PHA-665752 suppressed tumor growth in a tumor-transplanted mouse model.

Conclusion: Taken together, Met provided a druggable target for osteosarcoma and PHA665752 is a promising candidate for anti-osteosarcoma treatments.

Keywords: osteosarcoma, Met, PHA-665752, ERK signaling, LY3214996

\section{Introduction}

Osteosarcoma (OS) originates from primitive bone-forming mesenchymal stem cells and represents the most common primary bone malignancy in children and adolescents. ${ }^{1,2}$ Before the 1970s, amputation surgery was the main treatment for osteosarcoma due to the lack of effective chemotherapy. However, surgeries pose a negative impact on the quality of life, and displayed a limited efficacy with more than $80 \%$ of the patients still dying of lung metastasis. ${ }^{3}$ In the past 30 years, with the advent of advanced medical methods such as neoadjuvant chemotherapy, the overall 5-year survival rate of osteosarcoma has increased from $20 \%$ to $70 \%{ }^{4}$ The 


\section{Graphical Abstract}

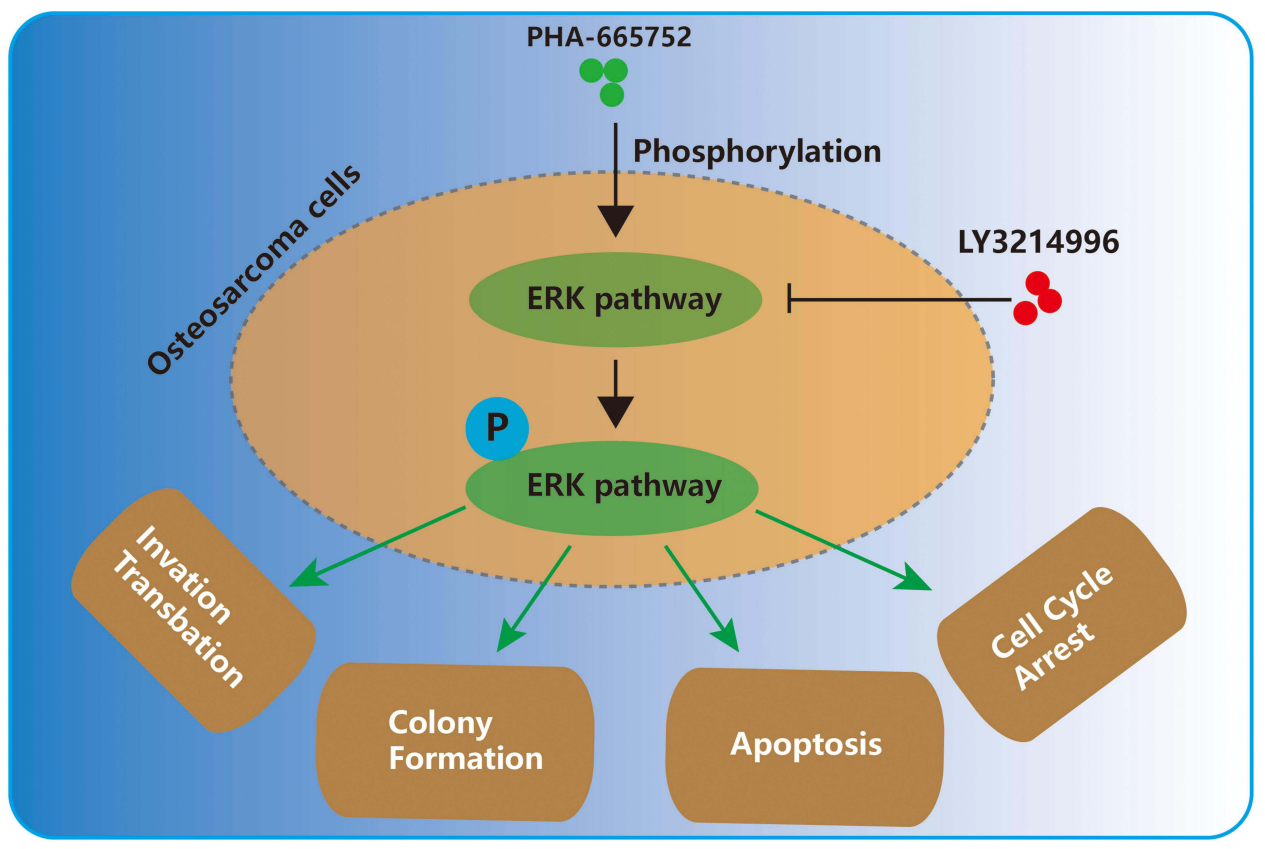

four basic drugs for osteosarcoma chemotherapy are methotrexate, cisplatin, doxorubicin and ifosfamide. High-dose methotrexate (HDMtx) therapy, such as MAP (methotrexate, doxorubicin, and cisplatin) has become the standard treatment in North America and Europe. ${ }^{5}$ However, for those with metastasis or drug resistance, the efficacy of chemotherapy is limited with an overall 5-year survival rate less than $20 \%{ }^{6,7}$ Therefore, novel treatments are urgently needed, especially against the emergence of drug resistance and effective for distant metastasis.

Hepatocyte growth factor (HGF) and its high-affinity receptor, mesenchymal epithelial transition factor (c-Met) serves multiple functions in embryonic development, ${ }^{8}$ organogenesis ${ }^{9}$ and wound healing. ${ }^{10}$ Previous studies also found that the physiological function of HGF/c-Met axis revolves around cell motility and invasive growth, and displayed a higher activity in many cancers. ${ }^{11-14}$

PHA-665752 is a potent, selective and ATP competitive c-Met inhibitor. As early as in 2003, Christensen et al ${ }^{15}$ have found that PHA-665752 could inhibit the c-metdependent phenotype in vitro and exhibit anti-tumor activity in vivo. Since then, Ma et $\mathrm{al}^{16}$ showed that PHA-665752 was able to cooperate with rapamycin to inhibit the growth of non-small cell lung cancer cells. Puri et $\mathrm{al}^{17}$ reported that PHA-665752 could inhibit the tumorigenicity and angiogenesis of lung cancer xenografts in mice to a degree reaching more than $85 \%$. However, the therapeutic effect of PHA-665752 in osteosarcoma remains uninvestigated. Based on its significant inhibition on other malignancies, we speculated that PHA-665752 also has a therapeutic effect on osteosarcoma.

Herein, we identified a novel c-Met inhibitor (PHA665752), which was able to suppress osteosarcoma progression via ERK signaling pathway. Our study provided a theoretical basis for the clinical use of PHA-665752 to treat osteosarcoma.

\section{Methods}

\section{OS Mouse Model}

All animal experiments were carried out according to the Guide for the Care and Use of Laboratory Animals published by the National Institutes of Health and approved by the Ethics Committee of Sir Run Run Shaw Hospital. Eighteen female BALB/c-nu mice, aged 4 weeks, were purchased from Slac Laboratory (Shanghai). About $2 \times 10^{7} 143 \mathrm{~B}$ cells were digested and mixed in $2 \mathrm{~mL}$ cold PBS. Then, a volume of $100 \mu \mathrm{L}$ cell suspension was injected subcutaneously. When the tumors in the dorsal area were macroscopic, mice were randomly divided into three groups (control group and two PHA-665752 groups) with six mice in each group. For the control group, 
a volume of $100 \mu \mathrm{L} 5 \%$ DMSO was injected into the peritoneum. While the PHA-665752 groups were received intraperitoneal injection of $100 \mu \mathrm{L}$ PHA-665752 $(7.5 \mathrm{mg} / \mathrm{kg}$ and $15 \mathrm{mg} / \mathrm{kg}$ ) diluted with $5 \%$ DMSO. The intraperitoneal injection was done every day, the body weight and tumor volume of mice were measured every 5 days. Thirty days later, the mice were sacrificed and the tumors were removed, weighted and fixed.

\section{Cell Culture}

143B (ATCC: CRL-8303) and U2OS (ATCC: HTB96TM) human osteosarcoma cells were obtained from the American Type Culture Collection (ATCC, Manassas, VA, USA). The cells were cultured in Dulbecco's Modified Eagle Medium (DMEM) supplemented with 10\% FBS (Thermo Fisher Scientific, Waltham, MA, USA). The culture was maintained in an incubator set to $37^{\circ} \mathrm{C}$ with $5 \% \mathrm{CO}_{2}$ and $100 \%$ humidity.

\section{Transfection}

Three different siRNAs of Met gene were designed and constructed by RiboBio (Guangzhou, China). The transfection of siRNAs was performed using Lipofectamine RNAiMAX (ThermoFisher), according to the manufacturer's instructions. Relative sequences are shown in Table 1.

\section{CCK8 Cell Proliferation Assay}

Treated 143B and U2OS cells were seeded into a 96-well plate at a density of $2 \times 10^{3}$ cells/well. The next day, cell proliferation was detected using CCK8 (Sigma-Aldrich), after $4 \mathrm{~h}$ of incubation, the absorbance of solution at 450 $\mathrm{nm}$ was measured using VersaMax microplate reader (Molecular Devices, CA, USA).

\section{Colony-Formation Assay}

Transfected or untreated cells were seeded into a 12-well plate at a density of $5 \times 10^{2}$ cells/well. In the drug treatment group, the medium was changed with fresh medium containing PHA-665752 (3-5 nM) or LY3214996 (5-40 nM) for about 14 days until the cells grew to visible colonies. The cells were washed with phosphate-buffered saline

Table I Sequences of Si/shRNAs Used in This Study

\begin{tabular}{|l|l|}
\hline Met si\#I & GGACTTTGTTGGACAATGA \\
Met si\#2 & CAATCATACTGCTGACATA \\
Met si\#3 & GTCGGAGGTTCACTGCATA \\
Met shRNA & GGACTTTGTTGGACAATGA \\
\hline
\end{tabular}

(PBS) and fixed with 4\% paraformaldehyde for $20 \mathrm{~min}$. Then, $0.5 \%$ crystal violet solution was used for staining, followed by image capture. Finally, the colonies were counted.

\section{Transwell Migration and Invasion Assay}

The migration and matrigel invasion assays were conducted using transwell chamber (for migration assay) or transwell precoated matrigel chamber (for invasion assay) according to the manufacturer's protocol (BD Science, Bedford, MA, USA). The homogeneous single-cell suspensions $\left(5 \times 10^{4}\right.$ cells/well for migration, $1 \times 10^{5} /$ well for invasion) were added to the upper chambers and incubated for $24 \mathrm{~h}$. In the drug treatment group, the cells were treated with PHA-665752 or LY3214996. The migration and invasion rates were quantified by counting the migratory and invasive cells at least three random fields.

\section{Wound-Healing Assay}

Transfected or untreated cells were seeded into a six-well plate at a density of $2 \times 10^{5}$ cells/well. In the drug treatment group, the cells were treated with PHA-665752 or LY3214996. For wound-healing assay, cells were scraped with the tip of $200 \mu \mathrm{L}$ pipette tips. All images were acquired using 10 high-power fields at 0 and $24 \mathrm{~h}$ after injury. Remodeling was measured as diminishing distance across the induced injury, normalized to the $0 \mathrm{~h}$ control, and expressed as relative migration.

\section{Western Blot}

Treated 143B and U2OS cells or tissues were lysed with radioimmunoprecipitation assay buffer (RIPA, Beyotime, China) supplemented with $100 \mathrm{mM}$ phenylmethanesulfonyl fluoride (PMSF) on ice. Total proteins were qualified using bicinchoninic acid (BCA) analysis (Beyotime, China). Then, proteins were separated by $8 \%$ SDS-PAGE and transferred to PVDF membranes (Bio-Rad), followed by blocking with 5\% nonfat milk at room temperature for $1 \mathrm{~h}$ and incubating with primary antibody at $4^{\circ} \mathrm{C}$ overnight. The next day, the membranes were washed by TBST and incubated with a secondary antibody at room temperature for $1 \mathrm{~h}$. Protein bands were visualized using FDbio-Femto ECL (Fudebio, Hangzhou, China) and a chemiluminescence system (BioRad, USA). Anti-GAPDH, anti-N-cadherin and antivimentin antibodies were purchased from Proteintech (Chicago, USA); Anti-Cyclin D1, anti-CDK4, anti-ERK1/2 and anti-pERK1/2 (Thy202/Tyr204) antibodies were purchased from Abcam (Cambridge, UK). 


\section{Quantitative RT-PCR}

Total RNA were extracted from 143B and U2OS cells using Ultrapure RNA Kit (CWBIO) according to the manufacturer's protocol. Quantification of Met gene was performed using UltraSYBR one step RT-qPCR Kit (CWBIO) according to the manufacturer's instructions. Each sample is repeated three times independently. The quantity of Met was normalized to GAPDH. Relative primers are shown in Table 2.

\section{Cell Apoptosis Assay by Flow Cytometry}

Transfected or untreated cells were seeded into a six-well plate at a density of $2 \times$ cells/well. In the drug treatment group, the cells were treated with PHA-665752 or LY3214996 for $24 \mathrm{~h}$. An Annexin V-FITC/propidium iodide (PI) kit (BD Biosciences, San Diego, CA, USA) was used according to the manufacturer's instructions. Cells were analyzed using a flow cytometer (BD FACSCANTO II, BD Biosciences, San Jose, CA, USA) and FlowJo software.

\section{Cell Cycle Assay by Flow Cytometry}

Transfected or untreated cells were seeded into a six-well plate at a density of $2 \times 10^{5}$ cells/well. In the drug treatment group, the cells were treated with PHA-665752 or LY3214996 for $24 \mathrm{~h}$. The cells were harvested, washed with PBS and fixed with cold $75 \%$ ethyl alcohol at $4{ }^{\circ} \mathrm{C}$ overnight. The next day, cells were washed twice with PBS and incubated with RNase A for $30 \mathrm{~min}$, followed by staining with $500 \mu \mathrm{L}$ propidium iodide for $30 \mathrm{~min}$ at room temperature. Cell cycle analysis was performed on the Accuri C6 (BD Biosciences, Mountain View, CA, USA).

\section{Histopathology and}

\section{Immunohistochemistry}

Tumor tissues were fixed in 4\% paraformaldehyde, embedded in paraffin and sectioned at $5 \mu \mathrm{m}$. The sections

Table 2 Primer Sequences Used in This Study

\begin{tabular}{|l|l|l|l|}
\hline $\begin{array}{l}\text { Primer } \\
\text { Set }\end{array}$ & $\begin{array}{l}\text { Gene } \\
\text { ID }\end{array}$ & Primers & Sequences \\
\hline GAPDH & 2597 & $\begin{array}{l}\text { Forward } \\
\text { Reverse }\end{array}$ & $\begin{array}{l}\text { AGCCACATCGCTCAGACAC } \\
\text { GCCAATACGACCAAATCC }\end{array}$ \\
\hline Met & 4233 & $\begin{array}{l}\text { Forward } \\
\text { Reverse }\end{array}$ & $\begin{array}{l}\text { AGCAATGGGGAGTGTAAAGAGG } \\
\text { CCCAGTCTTGTACTCAGCAAC }\end{array}$ \\
\hline
\end{tabular}

were incubated with primary antibodies at $4^{\circ} \mathrm{C}$ overnight. After washing thrice with PBST, the sections were incubated with a secondary antibody (Beyotime Institute of Biotechnology, Inc., Jiangsu, China) for $2 \mathrm{~h}$ at room temperature. The assessment was independently reviewed in parallel by two experienced pathologists.

\section{TUNEL Staining}

Tumor tissues were fixed in 4\% paraformaldehyde, embedded in paraffin and sectioned at $5 \mu \mathrm{m}$. An In Situ Cell Death Detection kit, POD (Sigma-Aldrich) was used for TUNEL staining according to the manufacturer's instructions. All images were acquired using a fluorescence microscope (Eclipse E600; Nikon Corporation, Tokyo, Japan).

\section{Statistical Analysis}

Statistical analysis was performed using the SPSS version 18.0 software (IBM Corporation, USA). Data were analyzed with Student's $t$-test, Fisher's Exact test, and oneway ANOVA. The results are presented as the mean $\pm \mathrm{SD}$. Group differences were considered statistically different for $\mathrm{p}<0.05$ between groups.

\section{Results}

\section{Silencing Met Inhibits the Proliferation, Migration and Invasion, and Promotes Apoptosis in OS Cells}

We examined the expression of Met in multiple OS cell lines (HOS, 143B, MG63, U2OS and SJSA-1) compared with hFOB1.19 cell line. Among the OS cell lines, 143B and U2OS cells exhibited the highest levels of Met (Supplementary Figure 1A). To explore the role of Met in OS cells (143B and U2OS), we first constructed a small hairpin RNA (shRNA) by selecting from three smallinterfering RNAs (siRNAs). After transfecting the shRNA into $143 \mathrm{~B}$ and U2OS cells, we found the expression level of Met considerably down-regulated. (Figure 1A). The results of the colony formation assay showed that the knockdown of Met expression considerably suppressed the colonyforming ability in OS cells (Figure 1B). As shown in Figure $1 \mathrm{C}$, transwell migration and invasion assay demonstrated that the migration and invasion of $143 \mathrm{~B}$ and U2OS cells were suppressed by the Met shRNA. These results were confirmed by wound-healing assay (Figure 1D). Moreover, Western blot analysis indicated that the expression of endothelial-mesenchymal transition (EMT) markers, including $\mathrm{N}$-cadherin and vimentin were significantly 
A
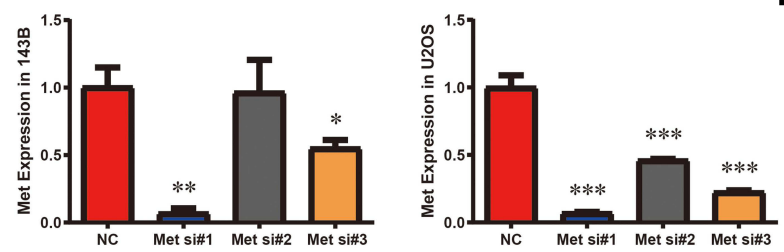

C
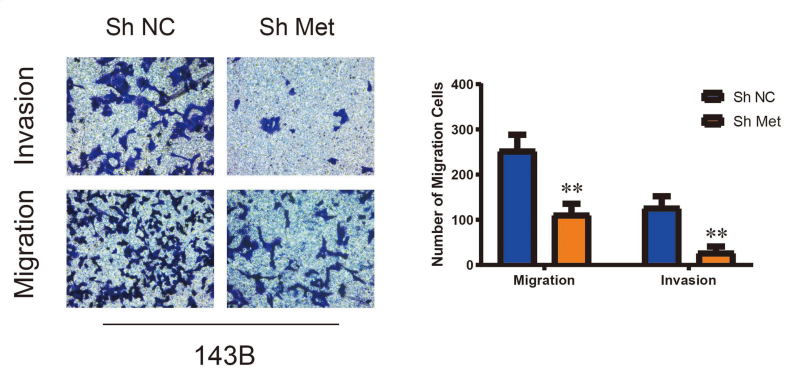

B
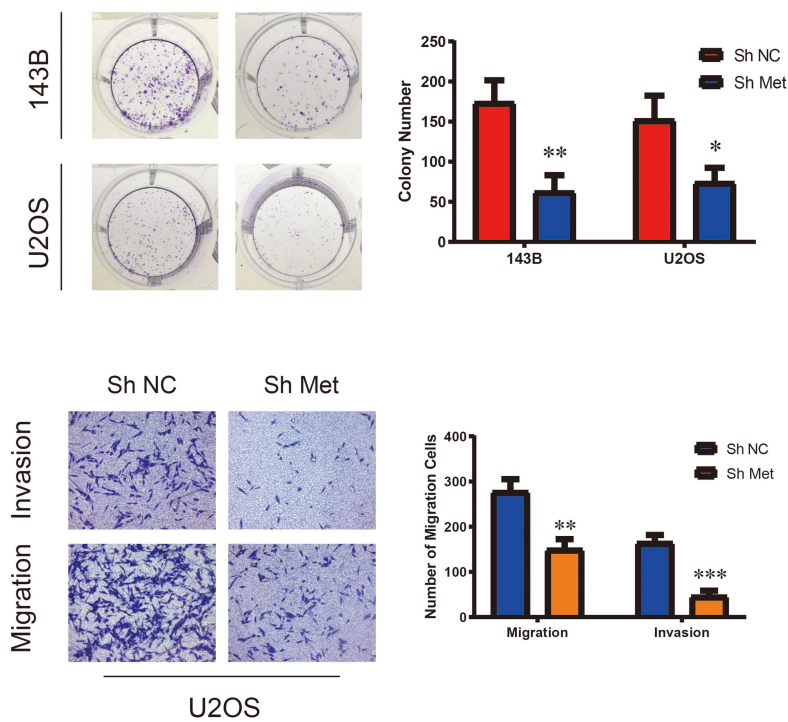

D

Sh NC

Sh Met
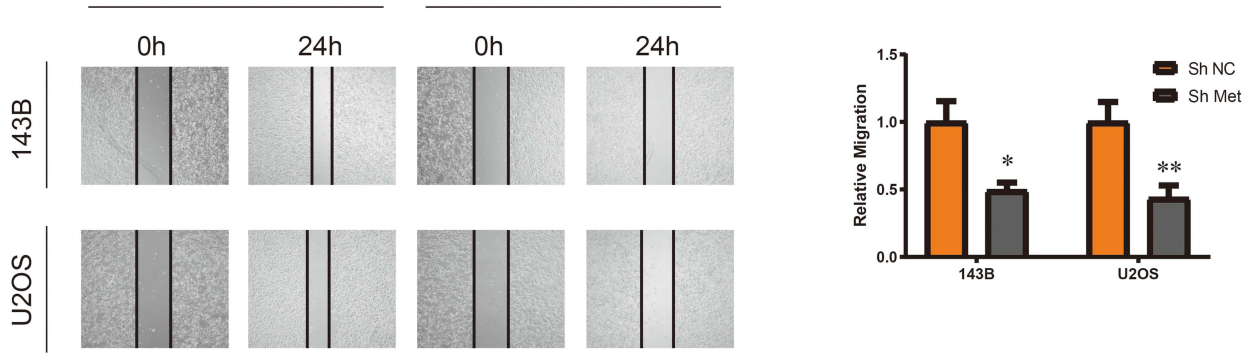

E

F
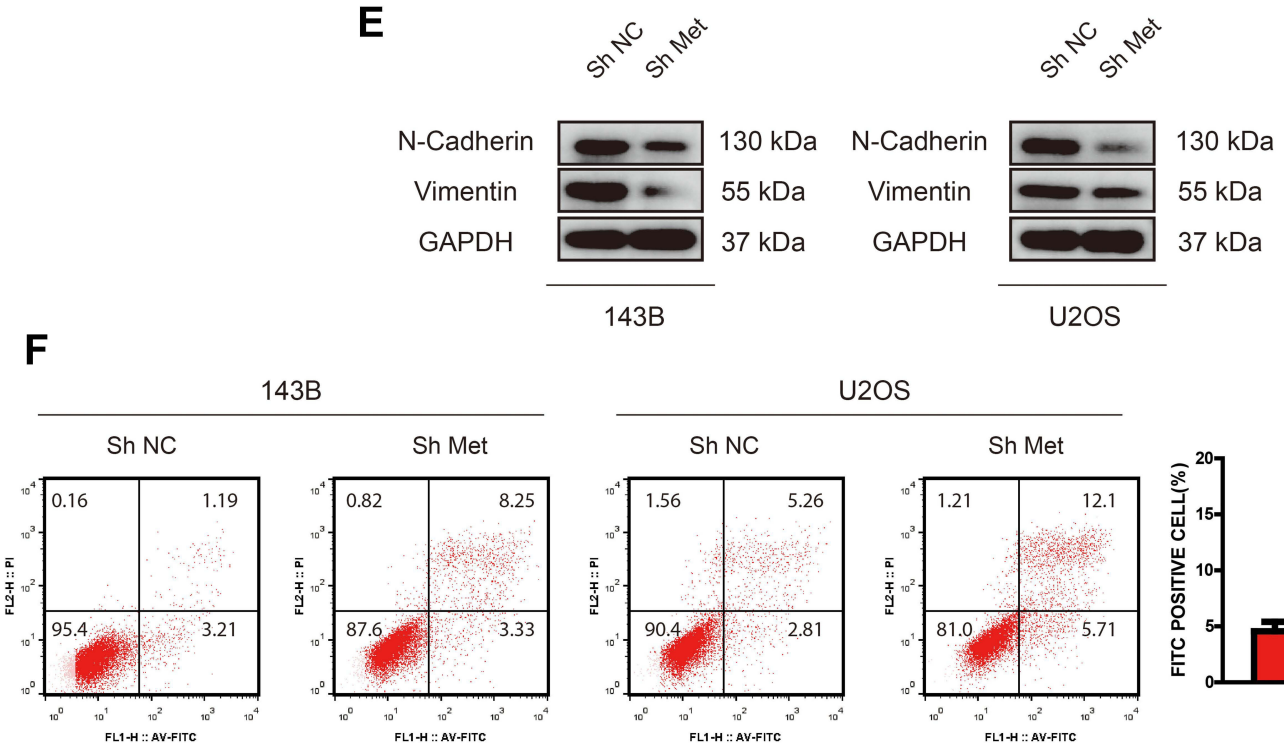

143B
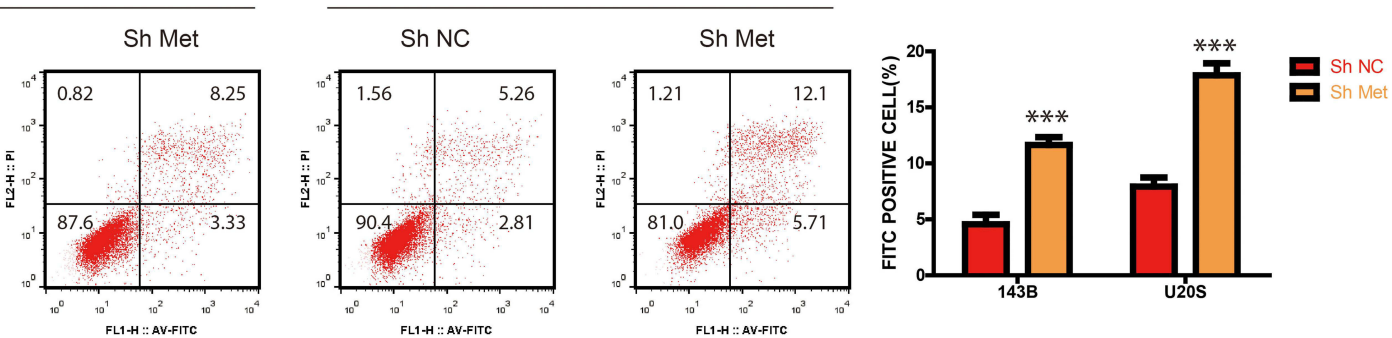

Figure I Silencing Met inhibits the proliferation, migration and invasion, while promotes apoptosis in OS cells. (A) The expression of Met after transfection of three different Met siRNAs in 143B and U2OS detected by qRT-PCR. $(n=3) * p<0.05$, ** $<<0.01$, **** $p<0.00$ I. (B) Colony-formation assay of I43B and U2OS after stable transfection of Met Sh Met or N.C. (vector plasmids). $(n=3) * p<0.05$, **p $<0.01$. (C) Transwell migration and invasion assay of I43B and U2OS after stable transfection of Met Sh Met or N.C. (vector plasmids). $(n=3) * * p<0.01$, **** $p<0.001$. (D) Wound-healing assay of I43B and U2OS after stable transfection of Met Sh Met or N.C. (vector plasmids). ( $\mathrm{n}=3$ ) $*_{p}<0.05$, **p<0.0I. (E) The expression of N-cadherin and vimentin in 143B and U2OS detected by Western blot analysis after stable transfection of Met Sh Met or N.C. (vector plasmids). (F) Cell apoptosis rate of I43B and U2OS after stable transfection of Met Sh Met or N.C. (vector plasmids). $(\mathrm{n}=3) * * * p<0.00$ I. 
downregulated upon Met knockdown (Figure 1E). We also performed cell apoptosis assay by flow cytometry, which showed that the downregulation of Met promoted cell apoptosis in both 143B and U2OS (Figure 1F). Taken together, these results demonstrated that Met was a tumor-promoting gene in OS cells. Silencing Met inhibited the proliferation, migration and invasion, and promoted apoptosis in OS cells.

\section{PHA-665752 Inhibits Proliferation, Migration and Invasion of OS Cells}

A novel selective c-Met inhibitor, PHA-665752, was acquired, and the molecular formula is shown in Figure 2A. To explore the function of PHA-665752 in OS cells, 143B and U2OS cells were treated with various concentration of PHA-665752 for $24 \mathrm{~h}$ (Figure 2B). The $\mathrm{IC}_{50}$ value was $3 \mathrm{nM}$ for 143B and U2OS. As shown in Figure 2C, treatment of PHA-665752 led to a compromised tumor formation. The migration and invasion of 143B and U2OS cells were suppressed by PHA-665752 in transwell migration and invasion assay (Figure 2D). Similar results were acquired by woundhealing assay (Figure 2E). Furthermore, N-cadherin and vimentin were significantly downregulated upon treatment of PHA-665752 (Figure 2F). Furthermore, to assess possible off-targets effects of c-Met inhibitor, we examined the function of PHA-665752 in Met-silenced OS cells, and the results showed that PHA-665752 could not play a role in Metsilenced OS cells (Supplementary Figure 1B-D), which indicated that c-Met was the specific target of PHA665752. Taken together, these results proved the protective role of PHA-665752 in osteosarcoma by inhibiting cell proliferation, migration and invasion in OS cells in a dosedependent manner.

\section{PHA-665752 Induces G0/GI Phase Arrest and Promotes Cell Apoptosis in OS Cells}

Considering the inhibiting function of PHA-665752, we treated OS cells with PHA-665752 for $24 \mathrm{~h}$ and performed cell cycle assay by flow cytometry afterwards. Results showed that PHA-665752 induced cell accumulation in the G1 phase, suggesting that PHA-665752 led to G0/G1 cell cycle arrest (Figure 3A). To elucidate the underlying mechanisms, expression levels of cycle-regulated proteins including CDK4 and Cyclin D1 were investigated by Western blot analysis. As shown in Figure 3B, treatment with PHA-665752 down-regulated CDK4 and Cyclin D1 expressions. Furthermore, TUNEL staining assay indicated that PHA-665752 promoted cell apoptosis in 143B and
U2OS (Figure 3C). These results suggested that PHA665752 induces G0/G1 phase arrest in OS cells by regulating the key regulators $\mathrm{G} 0 / \mathrm{G} 1$ transition and promoted apoptosis of OS cells.

\section{The ERKI/2 Pathway Mediates the Role of PHA-665752 in Proliferation, Migration and Invasion in OS Cells}

Accumulating evidences indicated that c-Met is canonically mediated by ERK1/2 pathway. ${ }^{18,19}$ Therefore, we speculated that PHA-665752 inhibits the proliferation, migration and invasion of OS cells through the ERK1/2 pathway. To verify this conjecture, we performed Western blot analysis and found that the expression of pERK $1 / 2$ in OS cells was considerably upregulated when treated with PHA-665752, while the expression of ERK1/2 had no change (Figure 4A). LY3214996 (Figure 4B), a highly selective inhibitor of the ERK1/2 pathway was then introduced in this study. We confirmed that LY3214996 downregulated pERK1/2 in OS cells as demonstrated by Western blot analysis, and the expression levels of N-cadherin and vimentin were downregulated under the treatment of PHA-665752, which was increased by adding LY3214996 (Figure 4C). 143B and U2OS were treated with $3 \mathrm{nM} / \mathrm{mL}$ of PHA665752 and various concentrations of LY3214996 for $24 \mathrm{~h}$. As shown in Figure 4D, the function of PHA-665752 was antagonized by LY3214996, which exhibited a ceiling effect when the concentration of LY3214996 exceeded $30 \mathrm{nM} /$ $\mathrm{mL}$. Therefore, subsequent experiments were performed with LY3214996 in a concentration of $30 \mathrm{nM} / \mathrm{mL}$. Colony-formation assay showed that LY3214996 reversed the results of impaired tumor formation induced by PHA-665752 (Figure 4E). The effects of PHA665752 on cell migration and invasion were also reversed by LY3214996 in transwell migration and invasion assay (Figure 4F). Similar results were acquired by wound-healing assay (Figure 4G). These results confirmed that the ERK1/2 pathway mediates the role of PHA-665752 in proliferation, migration and invasion in OS cells.

\section{LY32I 4996 Antagonizes PHA-665752 Induced G0/GI Phase Arrest and Apoptosis in OS Cells}

Since PHA-665752 inhibited cell proliferation by inducing G0/G1 phase arrest and ERK1/2 pathway mediated the 
A

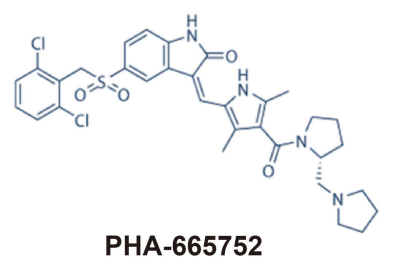

C

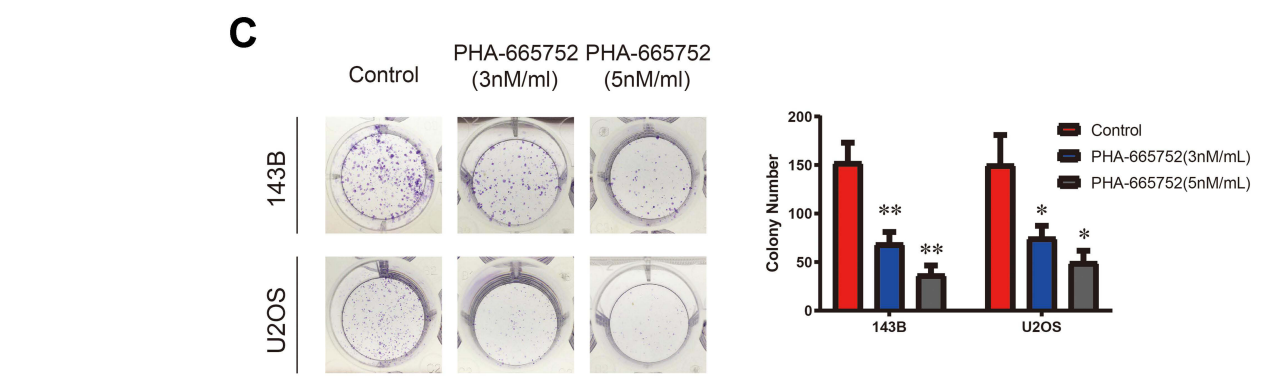

B

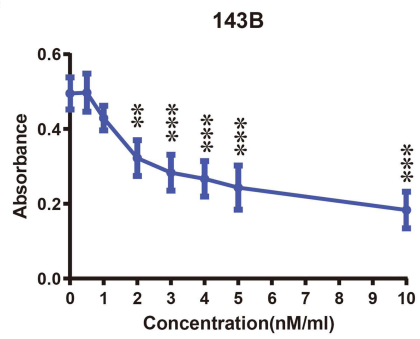

U2OS

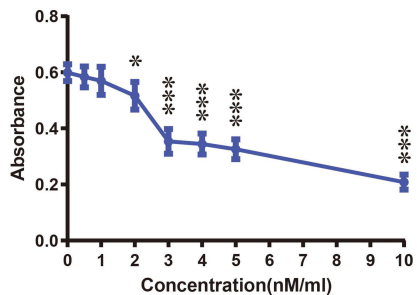

D

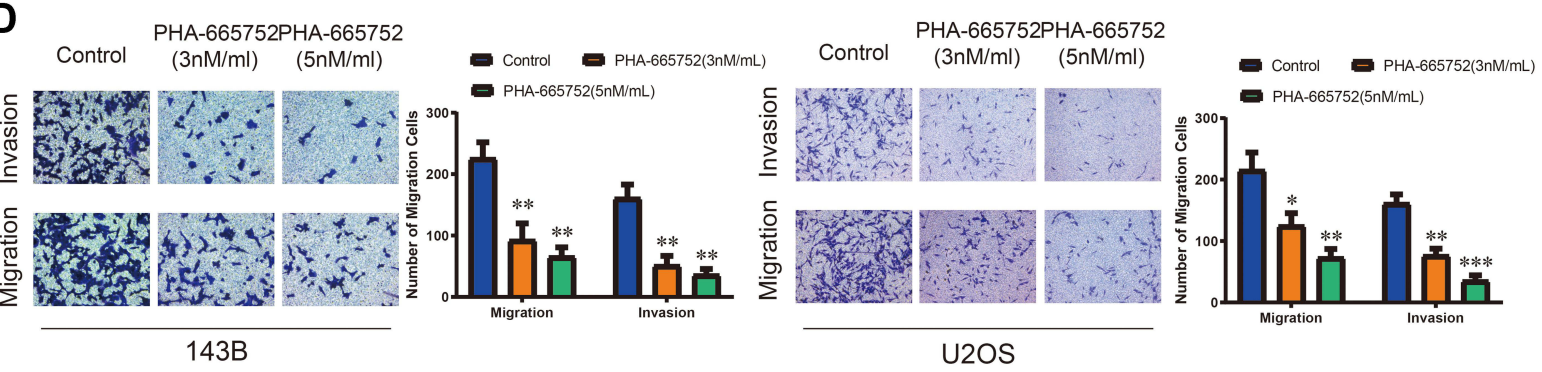

E
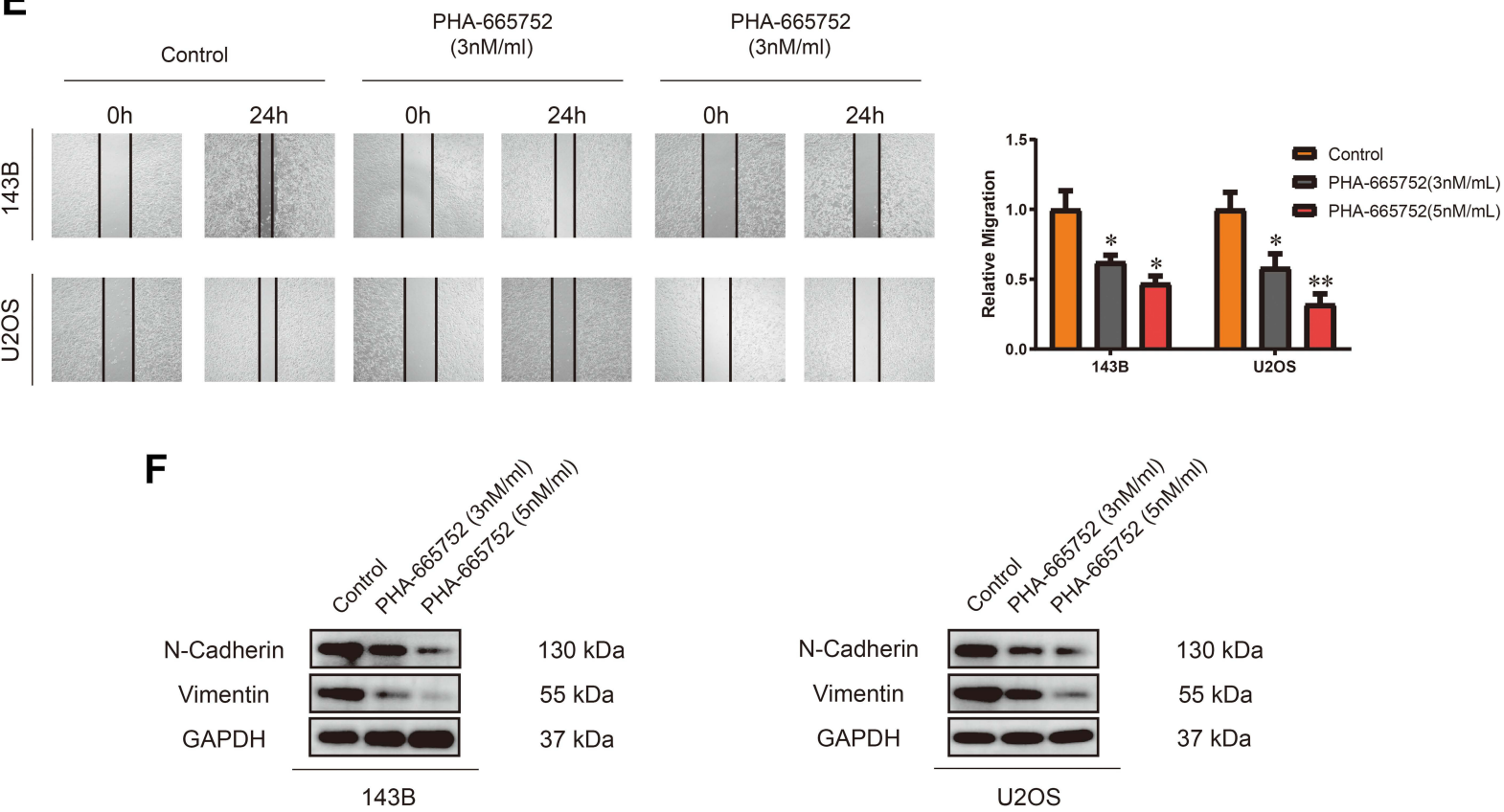

Figure 2 PHA-665752 inhibits proliferation, migration and invasion of OS cells. (A) The molecular formula of PHA-665752. (B) The anti-proliferative effect of PHA-665752 on I43B and U2OS was detected by CCK-8 assay. $(n=5)$ Cells were treated with different concentration of PHA-665752. Control group contained $0.1 \%$ DMSO. * $p<0.05$, ${ }^{* *} \mathrm{p}<0.01$, *** $<0.001$. (C) Colony-formation assay of I43B and U2OS with control or PHA-665752. ( $n=3$ ) ${ }^{\mathrm{p}}<<0.05$, **p $<0.01$. (D) Transwell migration and invasion assay of I43B and U2OS with control or PHA-665752. $(n=3) * p<0.05$, **p $<0.01$, *** $p<0.001$. (E) Wound-healing assay of I43B and U2OS with control or PHA-665752. ( $=3$ ) ${ }^{*} \mathrm{p}<0.05,{ }^{*} \mathrm{p}<0.01$. (F) The expression of $\mathrm{N}$-cadherin and vimentin in 143B and $\mathrm{U} 2 \mathrm{OS}$ with control or PHA-665752 detected by Western blot analysis. 


A Control $\quad \begin{array}{cc}\mathrm{PHA}-665752 & \mathrm{PHA}-665752 \\ (3 \mathrm{nM} / \mathrm{ml}) & (5 \mathrm{nM} / \mathrm{ml})\end{array}$
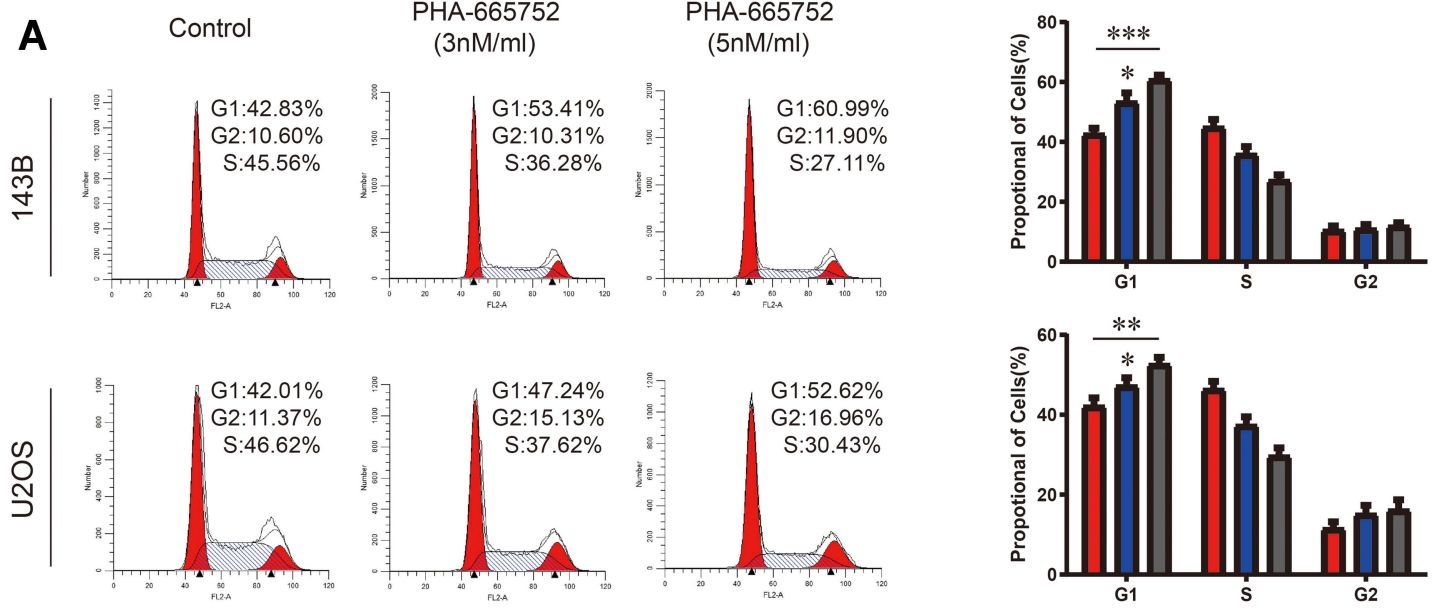

- Control

- PHA-665752(3nM/ml)

- PHA-665752(5nM/mi)

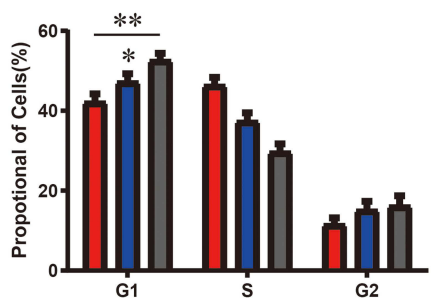

Control

- $\mathrm{PHA}-665752(3 \mathrm{nM} / \mathrm{ml})$

- PHA-665752(5nM/ml)

B
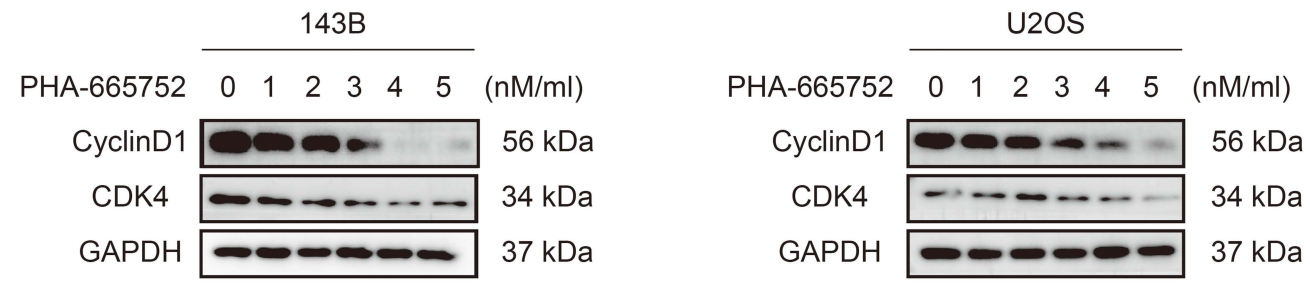

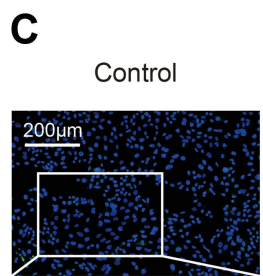

\begin{abstract}
PHA-665752
$(3 \mathrm{nM} / \mathrm{ml})$
\end{abstract}
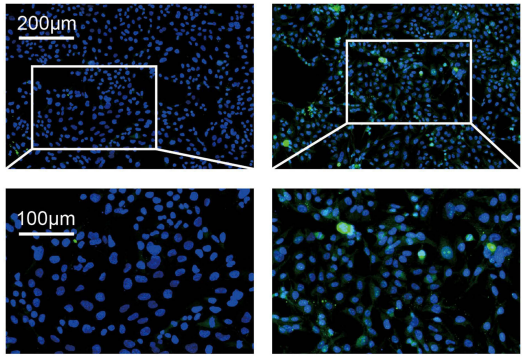

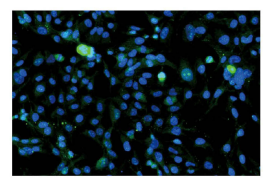

143B
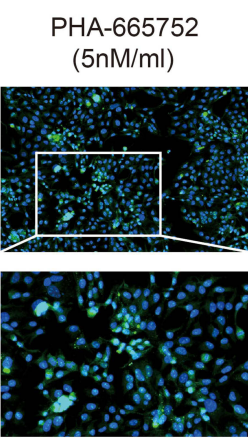

somess

143B

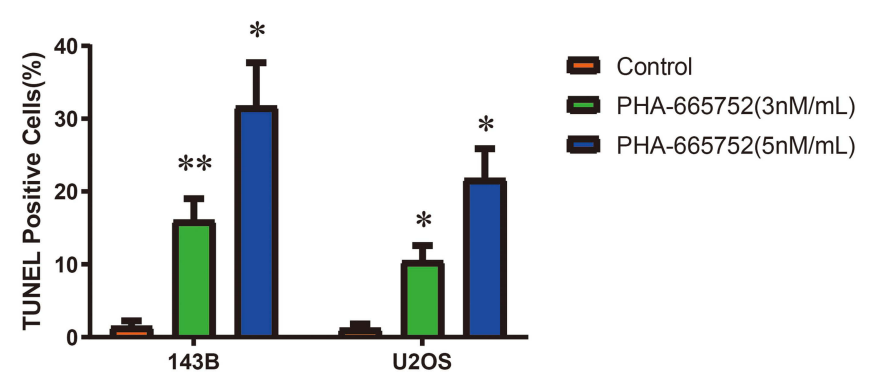

Figure 3 PHA-665752 induces G0/GI phase arrest and promotes cell apoptosis in OS cells. (A) Cell cycle assay of I43B and U2OS with control or PHA-665752. (n=3) ${ }^{*} \mathrm{p}<0.05$, ** $<<0.01, * * * \mathrm{p}<0.001$. (B) The expression of Cyclin DI and CDK4 in 143B and U2OS was detected by Western blot analysis. Cells were treated with different concentration of PHA-665752. (C) TUNEL staining assay of I43B and U2OS with control or PHA-665752. Scale bars, 100 $\mu \mathrm{m}$ and $200 \mu \mathrm{m}$. $(\mathrm{n}=3){ }^{*} \mathrm{p}<0.05$, ** $\mathrm{p}<0.01$. 

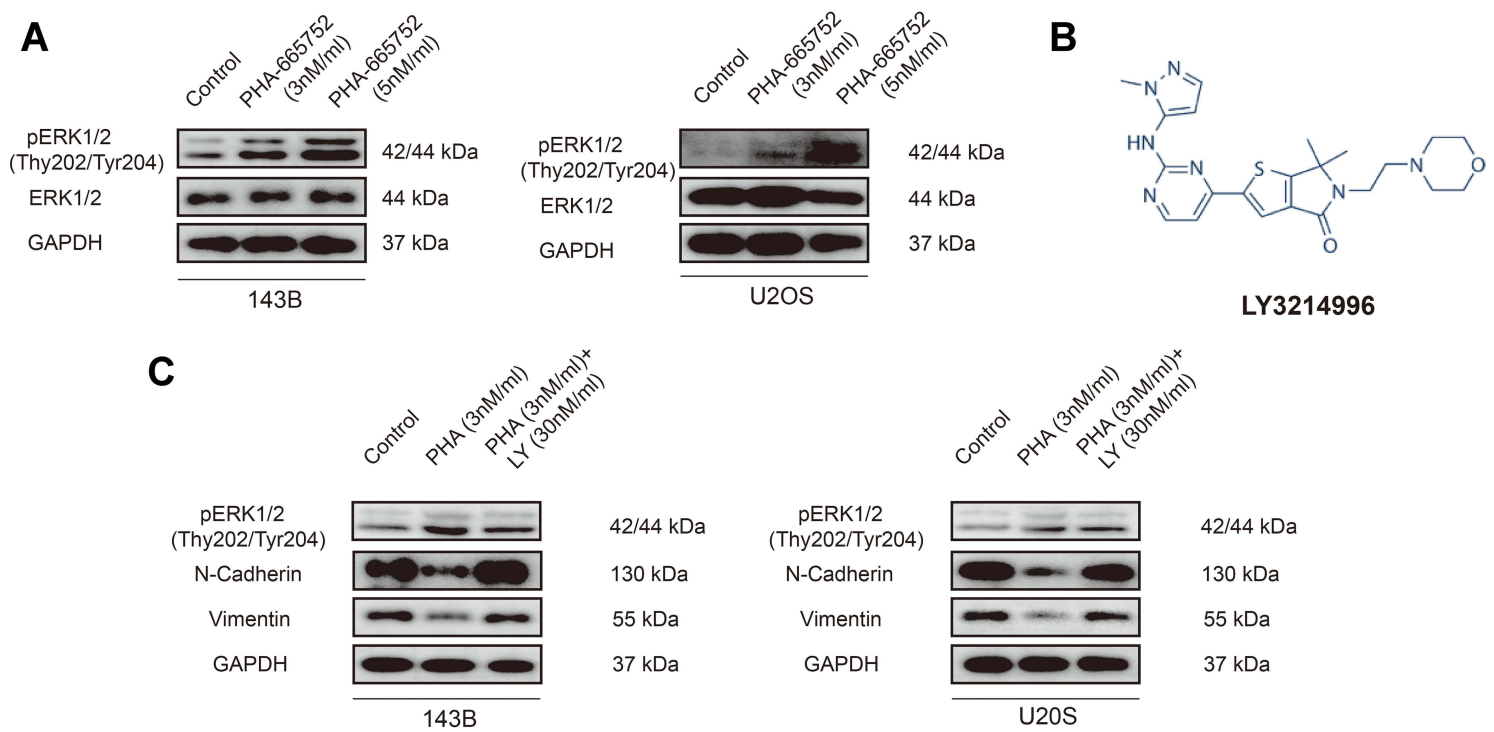

$\begin{array}{lc}42 / 44 \mathrm{kDa} & \begin{array}{c}\text { pERK1/2 } \\ \text { (Thy202/Tyr204) }\end{array} \\ 130 \mathrm{kDa} & \text { N-Cadherin } \\ 55 \mathrm{kDa} & \text { Vimentin } \\ 37 \mathrm{kDa} & \text { GAPDH }\end{array}$

D

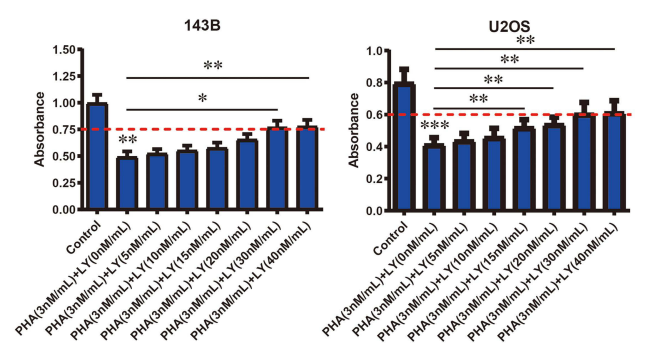

E

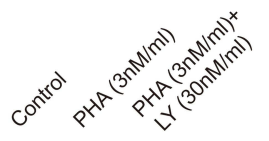

LY3214996
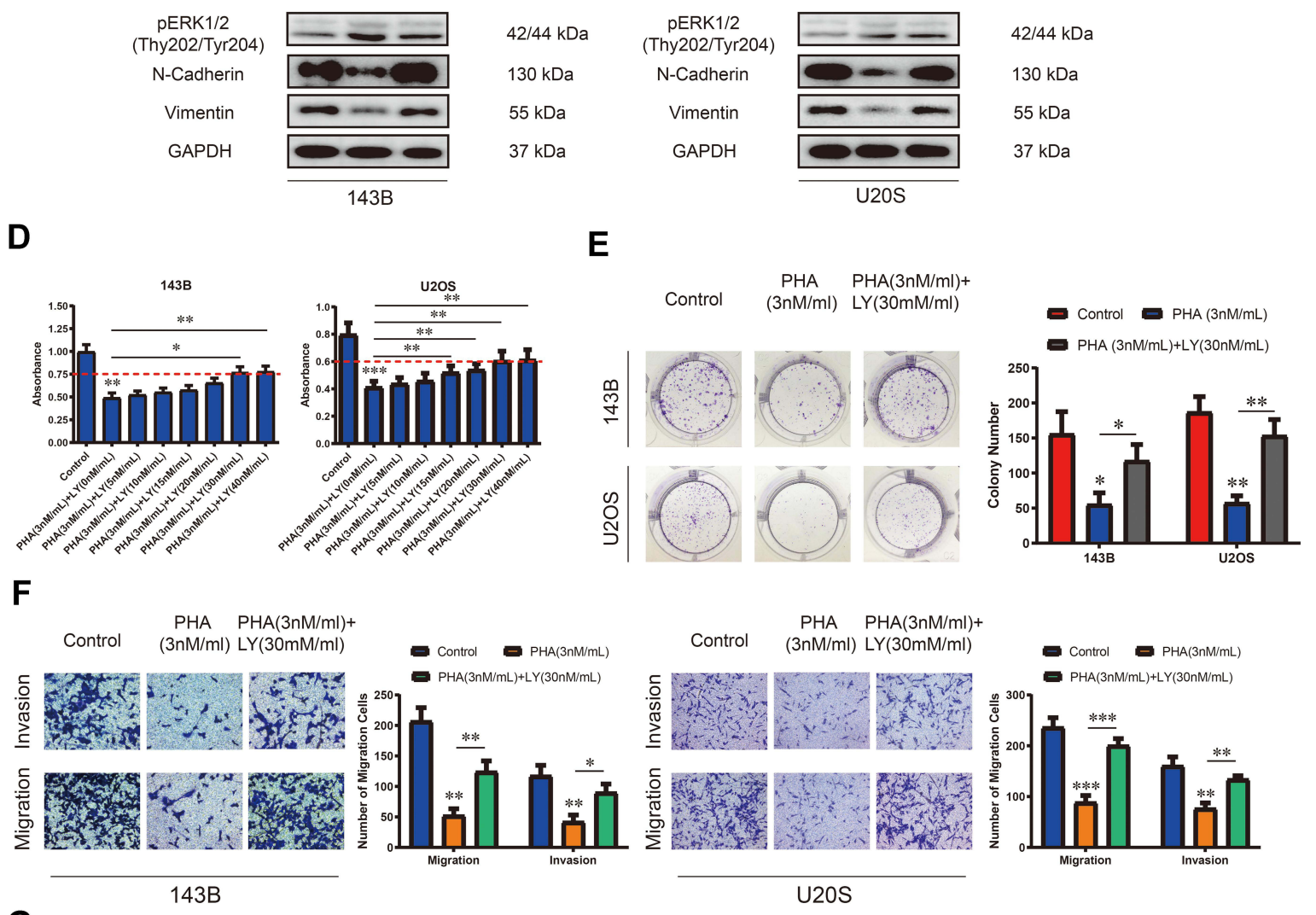

G
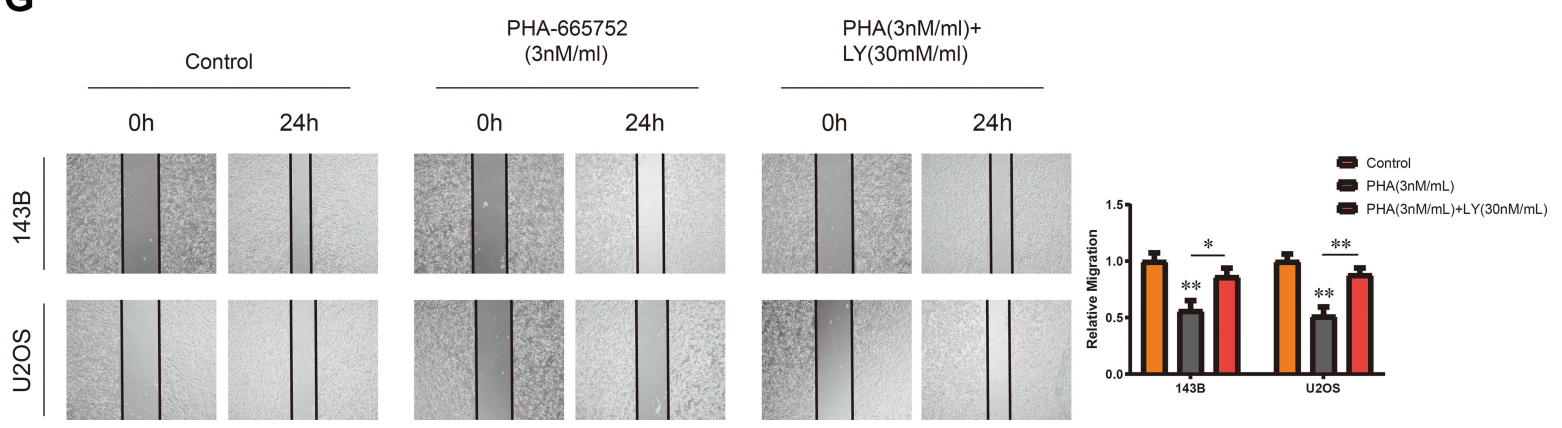

Figure 4 The ERKI/2 pathway mediates the role of PHA-665752 in proliferation, migration and invasion in OS cells. (A) The expression of ERKI/2 and pERKI/2 (Thy202/Tyr204) in I43B and U2OS was detected by Western blot analysis. Cells were treated with different concentration of PHA-665752. (B) The molecular formula of LY32 I4996. (C) The effects of PHA-665752 and LY32 I4996 on the expression of PERKI/2 (Thy202/Tyr204), N-cadherin and vimentin in OS cells as demonstrated by Western blot assay. (D) Proliferation of OS cells treated with PHA-665752 (3nM/mL) and various concentrations of $L Y 3214996$ was evaluated by $C C K-8$ assay. $(n=5) * p<0.05$, ${ }^{* *} p<0.01$, *** $p<0.001$. (E) The effects of PHA-665752 and LY32 I 4996 on the colony-formation ability in OS cells as demonstrated by colony-formation assay. $(n=3) * p<0.05$, *** $<<0.01$. (F) Transwell migration and invasion assay demonstrated the effects of PHA-665752 and LY32 14996 on the migration and invasion ability in OS cells. $(n=3) * p<0.05$, ** $p<0.01$. Wound-healing assay of demonstrated the effects of PHA-665752 and LY32 I 4996 on the migration ability in OS cells. $(n=3){ }^{*}<<0.05$, ${ }^{* *} p<0.0$ I. (G) The effects of PHA-665752 and LY 32 I 4996 on the migration ability in OS cells as demonstrated by woundhealing assay. $(n=3){ }^{*} p<0.05$, ${ }^{* *} p<0.01$. 
proliferation-promoting function of PHA-665752, we then performed cell cycle assay by flow cytometry after treating with PHA-665752 and LY3214996 for $24 \mathrm{~h}$. As shown in Figure 5A, PHA-665752 led to G0/G1 cell cycle arrest in OS cells, and the arrest effect was canceled after LY3214996 was added. The Western blot analysis showed that the effects of PHA-665752 on CDK4 and Cyclin D1 were also reversed by LY3214996 (Figure 5B). Furthermore, TUNEL staining assay demonstrated that LY3214996 decreased cell apoptosis rate in OS cells (Figure 5C). Taken together, these results indicated that LY3214996 antagonized PHA-665752-induced G0/G1 phase arrest and apoptosis in OS cells.

\section{PHA-665752 Inhibits Growth of Osteosarcoma in vivo}

A tumor-transplanted mouse model was introduced in this study to investigate the effect of PHA-665752 in vivo (Figure 6A). PHA-665752 at doses of $7.5 \mathrm{mg} / \mathrm{kg}$ and $15 \mathrm{mg} / \mathrm{kg}$ both resulted in considerably decreased tumor volume and weight after 24 days of drug administration, and $15 \mathrm{mg} / \mathrm{kg}$ of PHA-665752 showed a more obvious effect (Figure 6B-E). However, there were no obvious differences of body weight among the three groups (Figure 6F). TUNEL staining assay showed significantly increased apoptosis cells in PHA-665752-treating groups with higher TUNEL-positive cell rate in $15 \mathrm{mg} / \mathrm{kg}$ of PHA665752 (Figure 6G). As shown in Figure 6H and J, PHA665752 treatment led to an increase in the level of pERK1/ 2 , while a decreased level of $\mathrm{N}$-cadherin and Cyclin-D1 in a dose-dependent manner. The major organs, including heart, liver, kidney, lung and spleen, were collected to investigate the potential cytotoxic effects of PHA-665752 on normal tissues. Hematoxylin and eosin (H\&E) staining of organs revealed no major organ-related toxicities of PHA-665752 (Figure 6I). These results showed that PHA-665752 exhibited potent antitumor activity with low toxicity in vivo.

\section{Discussion}

Current treatment of osteosarcoma mainly includes surgical intervention and systemic chemotherapy. This yields an overall 5-year survival rate of approximately $70 \%$ for patients with localized osteosarcoma. However, the survival rate plunges to less than $20 \%$ for patients with metastatic or recurrent disease. ${ }^{7,20}$ A major, as yet unsolved, problem is the dismal prognosis for patients with unresectable or relapsed osteosarcomas. Novel approaches and molecular targets are needed to improve prognosis. ${ }^{4}$

Aberrant activation of the HGF/c-Met signaling pathway was reported to be associated with several tumors, including cervical cancer, ${ }^{21}$ non-small-cell lung cancer ${ }^{22}$ and gastrointestinal cancer. ${ }^{23}$ However, as the most common primary bone malignancy, the role of $\mathrm{HGF} / \mathrm{c}-\mathrm{met}$ signaling pathway in osteosarcoma was less studied. With the in-depth study of c-Met gene, researches have confirmed that c-Met oncogene plays a crucial role in OS initiation and progression, and some of its inhibitors were proved to be effective for the treatment of osteosarcoma. Fioramonti et $\mathrm{al}^{24}$ Reported that a c-Met inhibitor cabozantinib affects osteosarcoma growth through a direct effect on tumor cells and modifications in bone microenvironment. Sampson et $\mathrm{al}^{25}$ showed met inhibitor PF2341066 inhibits osteosarcoma growth and osteolysis/ matrix production in a xenograft model. In our present study, we used loss-of-function approaches in vitro and demonstrate that Met gene was an oncogene in osteosarcoma, mainly by promoting cell proliferation, migration and invasion, and inhibiting cell apoptosis in 143B and U2OS. Therefore, HGF/c-Met signaling pathway serves as a promising candidate for osteosarcoma treatment.

PHA-665752, a novel c-Met inhibitor, was introduced in this study, with an $\mathrm{IC}_{50}$ value of $3 \mathrm{nM}$ for $143 \mathrm{~B}$ and U2OS. The role of PHA-665752 was investigated in this study. We found that PHA-665752 could inhibit cell proliferation, migration and invasion in OS cells in a dosedependent manner. Previous researches have only reported the role of PHA-665752 in OS cells migration and invasion. $^{26,27}$ In this study, we found PHA-665752 induced G0/G1 phase arrest and promoted cell apoptosis through the key regulators of $\mathrm{G} 0 / \mathrm{G} 1$ transition. Moreover, in a tumor-transplanted mouse model, we exhibited the potent antitumor activity of PHA-665752 as well as its low toxicity in vivo for the first time.

Previous studies demonstrated that c-Met were canonically mediated by ERK $1 / 2$ pathway and PI3K-AKT pathway. $^{26,28,29}$ The ERK signaling is activated by numerous extracellular signals and was reported to participate in various biological cellular functions, including proliferation, migration and differentiation. ${ }^{30,31}$ Most cancer-associated lesions leading to an activation of ERK signaling occur early in the pathway. ${ }^{32}$ Our results further indicated that ERK signaling pathway was activated by PHA-665752, while LY3214996, a highly selective inhibitor of the ERK1/ 2 pathway, significantly downregulated the expression of 
A
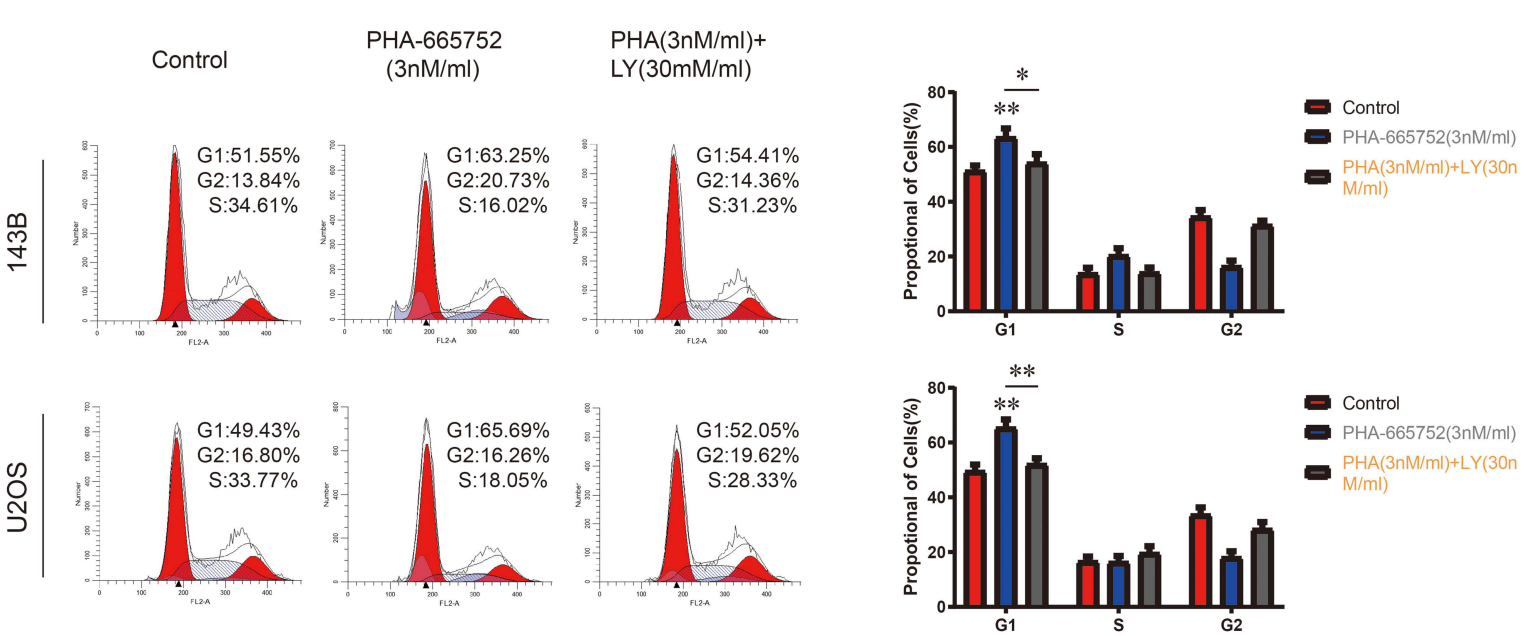

B
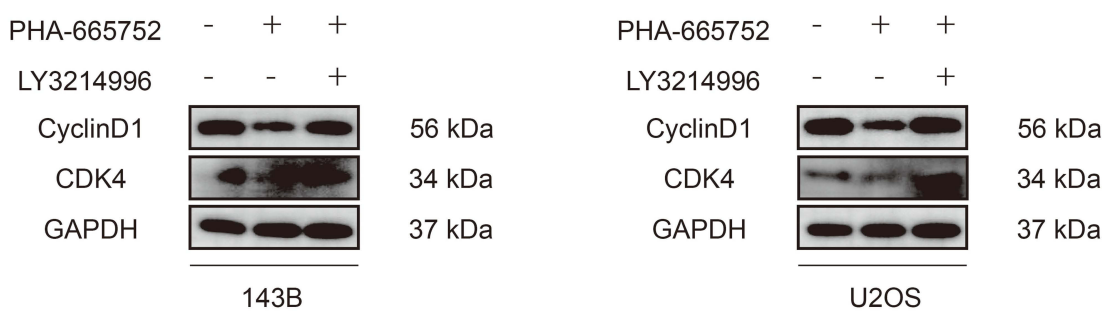

C

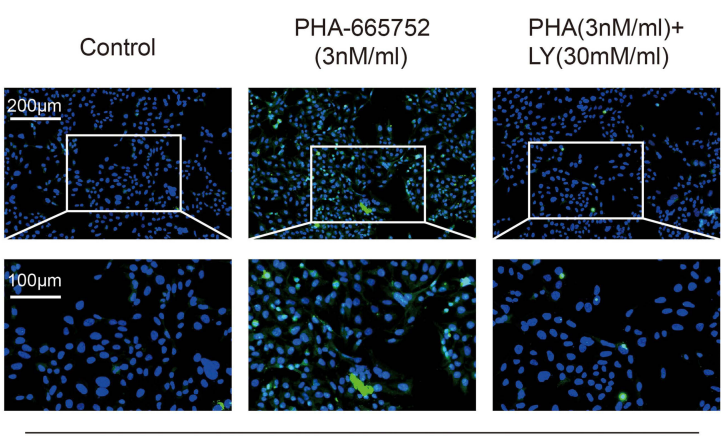

143B

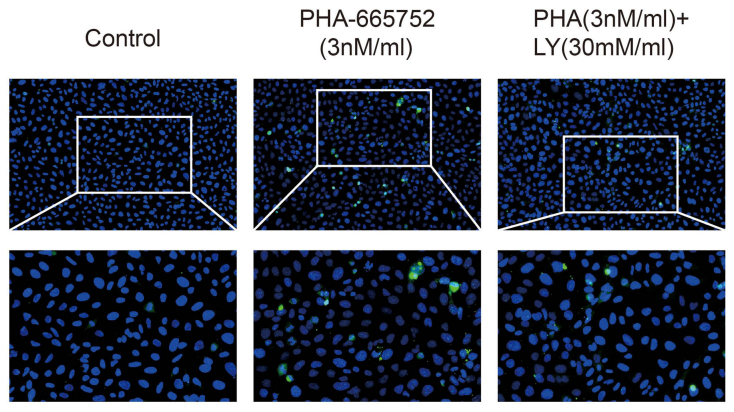

U2OS

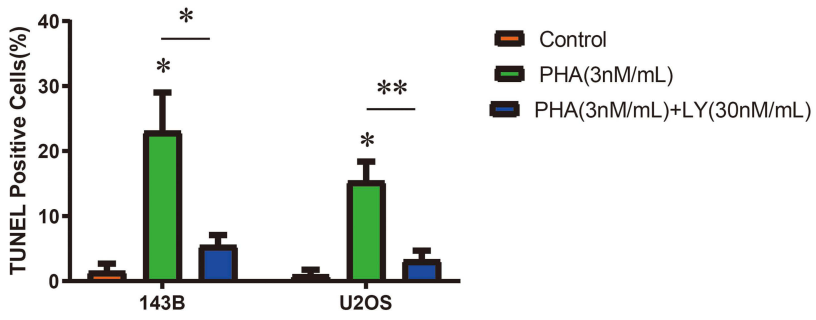

Figure 5 LY32I4996 antagonizes PHA-665752 induced G0/GI phase arrest and apoptosis in OS cells. (A) Cell cycle assay of I43B and U2OS was performed when treated with PHA-665752 and LY3214996. $(n=3) * p<0.05$, ** $p<0.01$. (B) The expression of Cyclin DI and CDK4 in I43B and U2OS among the above three groups was detected by Western blot analysis. (C) The effects of PHA-665752 and LY3214996 on cell apoptosis in I43B and U2OS as demonstrated by TUNEL staining assay. Scale bars, I00 $\mu$ m and $200 \mu \mathrm{m} .(n=3) * \mathrm{p}<0.05, * * \mathrm{p}<0.01$. 

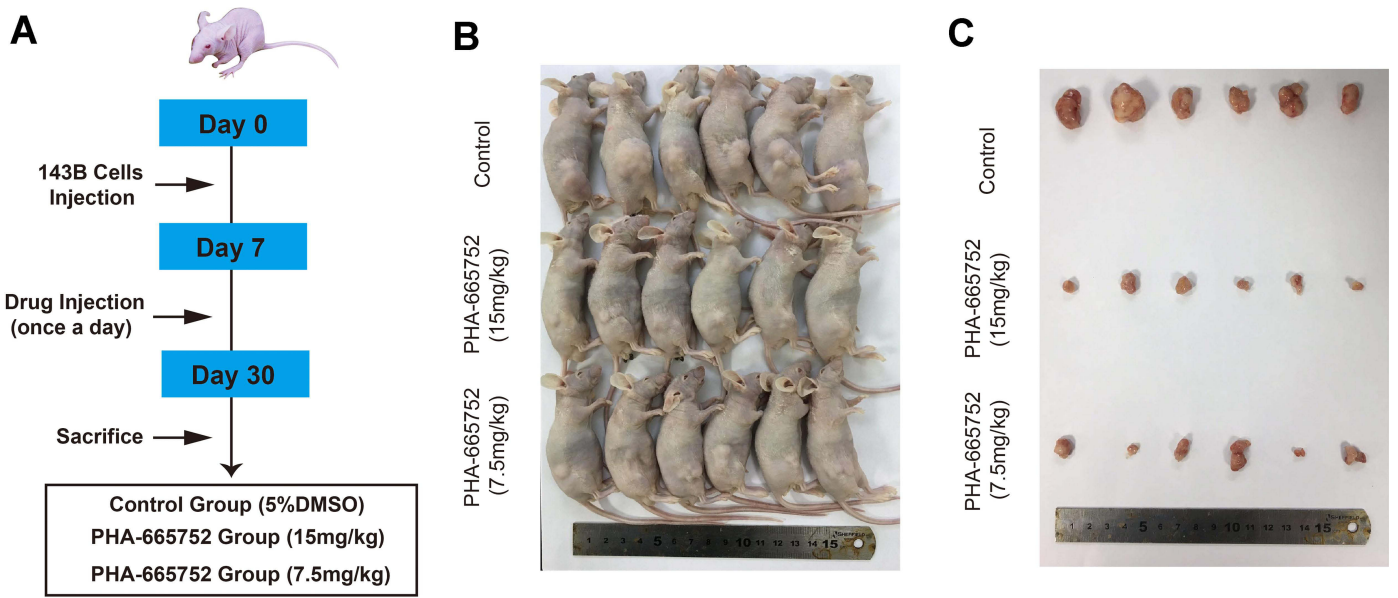

D

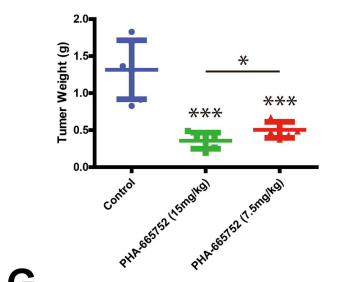

G

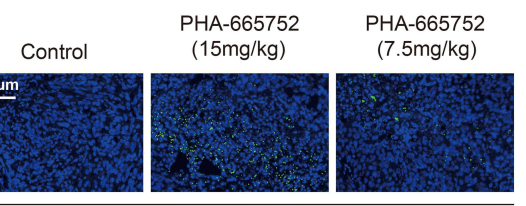

TUNEL Staining

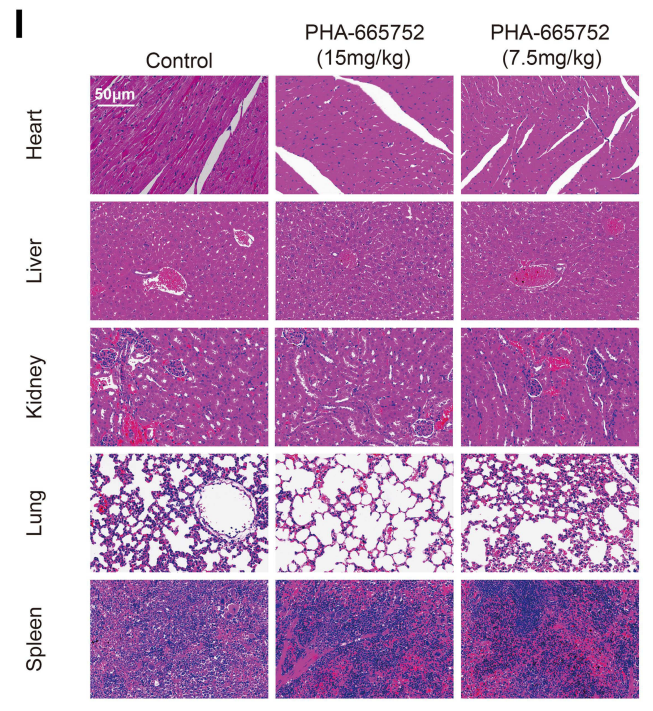

E

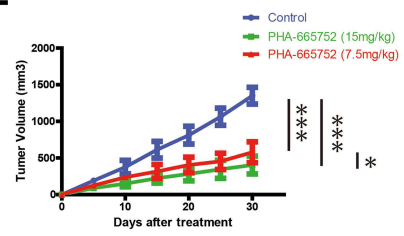

F

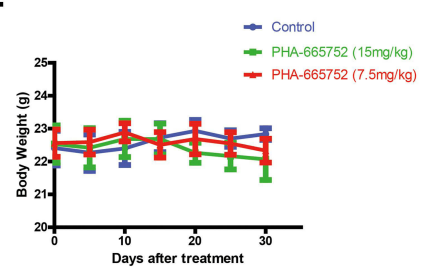

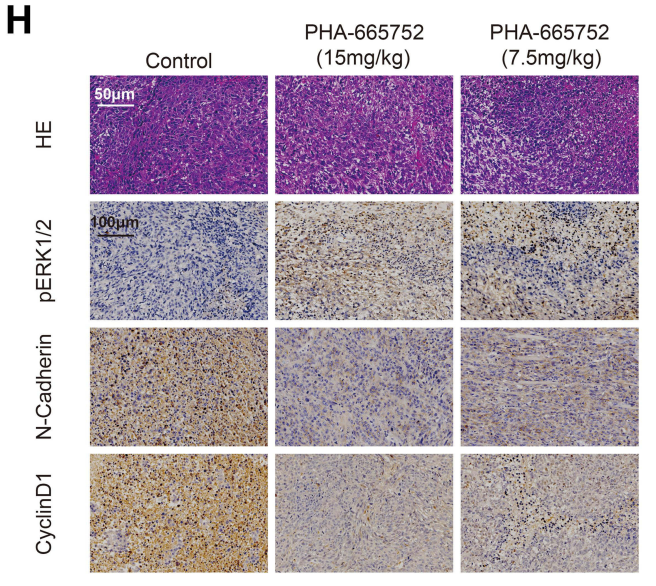

J

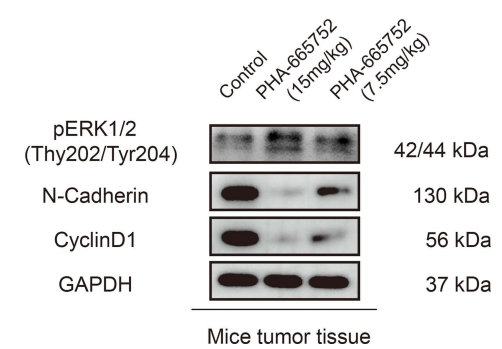

Figure 6 PHA-665752 inhibits growth of osteosarcoma in vivo. (A) Establishment of a tumor-transplanted mouse model. (B and C) BALB/c-nu mice were injected subcutaneously with about $2 \times 10^{7} \mathrm{I} 43 \mathrm{~B}$ cells. One week after tumor inoculation, mice were randomly divided into three groups with six mice in each group. For control group, a volume of $100 \mu \mathrm{L} 5 \%$ DMSO was injected into the peritoneum. While the PHA-665752 groups were received intraperitoneal injection of $100 \mu \mathrm{L}$ PHA-665752 $(7.5 \mathrm{mg} / \mathrm{kg}$ and $15 \mathrm{mg} / \mathrm{kg}$ ) diluted with $5 \%$ DMSO. The intraperitoneal injection was done every day. Tumors were dissected, photographed, and weighed after 30 days. (D) Tumor weight was calculated at the end of the experiment. $(n=6){ }^{*} p<0.05$, $*_{*} *_{p}<0.00 I$. (E) Tumor weight was measured every five days. $(n=6){ }^{*} p<0.05$, **** $p<0.00 I$. (F) Body

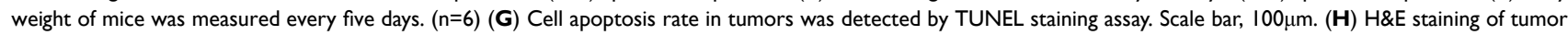

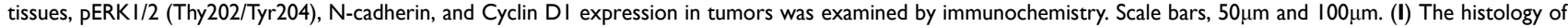

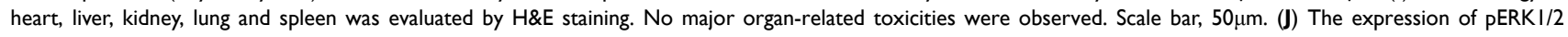
(Thy202/Tyr204), N-cadherin, and Cyclin DI in tumors was evaluated by Western blot analysis. 
pERK1/2 and antagonized the effects of PHA-665752 in osteosarcoma. We demonstrated that PHA-665752 suppressed osteosarcoma progression via the ERK1/2 pathway.

However, inhibiting the ERK1/2 pathway failed to completely reverse the effects of PHA-665752, suggesting the presence of other downstream pathways of PHA665752. Moreover, we proved that ERK1/2 pathway was an important mediator of PHA665752 in osteosarcoma, though the specific target of the PHA-665752 -ERK1/2 interaction was unknown, which merit additional studies and further clarification.

In conclusion, we found a c-Met inhibitor, PHA665752, effective in suppressing osteosarcoma progression via the ERK1/2 pathway. Meanwhile, it posed little toxicity in vivo. Our study provided a theoretical basis for the clinical use of PHA-665752 to treat osteosarcoma.

\section{Conclusions}

This study demonstrates that met provided a druggable target for osteosarcoma, and PHA-665752 is a promising candidate for anti-osteosarcoma treatments, which suppress osteosarcoma progression via the ERK1/2 pathway in human osteosarcoma cells.

\section{Ethics Approval and Consent to Participate}

The study design was approved by the Ethics Committee of Sir Run Run Shaw Hospital.

\section{Acknowledgments}

The authors gratefully acknowledge all the people who helped us to do this project.

\section{Author Contributions}

All authors contributed to data analysis, drafting or revising the article, have agreed on the journal to which the article will be submitted, gave final approval of the version to be published, and agree to be accountable for all aspects of the work.

\section{Funding}

This study was sponsored by Innovative Talents Support Plan Program of Zhejiang Province (2020383422). No benefits in any form have been or will be received from a commercial party related directly or indirectly to the subject of this manuscript.

\section{Disclosure}

The authors have declared that no competing interests exist.

\section{References}

1. Lindsey BA, Markel JE, Kleinerman ES. Osteosarcoma overview. Rheumatol Ther. 2017;4:25-43. doi:10.1007/s40744-016-0050-2

2. Gorlick R, Anderson P, Andrulis I, et al. Biology of childhood osteogenic sarcoma and potential targets for therapeutic development: meeting summary. Clin Cancer Res. 2003;9:5442-5453.

3. Bishop MW, Janeway KA, Gorlick R. Future directions in the treatment of osteosarcoma. Curr Opin Pediatr. 2016;28(1):26-33. doi:10.1097/MOP.0000000000000298

4. Ritter J, Bielack SS. Osteosarcoma. Ann Oncol. 2010;21(Suppl 7): vii320-vii325. doi:10.1093/annonc/mdq276

5. Rastogi S, Aggarwal A, Tiwari A, Sharma V. Chemotherapy in nonmetastatic osteosarcoma: recent advances and implications for developing countries. J Glob Oncol. 2018;4:1-5.

6. Burns J, Wilding CP, Jones RL, Huang PH. Proteomic research in sarcomas - current status and future opportunities. Semin Cancer Biol. 2020;61:56-70.

7. Harrison DJ, Geller DS, Gill JD, Lewis VO, Gorlick R. Current and future therapeutic approaches for osteosarcoma. Expert Rev Anticancer Ther. 2018;18(1):39-50. doi:10.1080/14737140.2018.141 3939

8. Latimer AJ, Jessen JR. Hgf/c-met expression and functional analysis during zebrafish embryogenesis. Dev Dyn. 2008;237(12):3904-3915. doi:10.1002/dvdy.21794

9. Trusolino L, Bertotti A, Comoglio PM. MET signalling: principles and functions in development, organ regeneration and cancer. Nat Rev Mol Cell Biol. 2010;11(12):834-848. doi:10.1038/nrm3012

10. Chalenko YM, Sysolyatina EV, Sobyanin KA, et al. Topical treatment with the bacterium-derived c-Met agonist InlB321/15 accelerates healing in the abrasion wound mouse model. Arch Dermatol Res. 2018;310(10):849-856. doi:10.1007/s00403-018-1870-4

11. Refaat T, Donnelly ED, Sachdev S, et al. c-Met overexpression in cervical cancer, a prognostic factor and a potential molecular therapeutic target. Am J Clin Oncol. 2017;40(6):590-597. doi:10.1097/ COC.0000000000000203

12. Szturz P, Budikova M, Vermorken JB, et al. Prognostic value of c-MET in head and neck cancer: a systematic review and meta-analysis of aggregate data. Oral Oncol. 2017;74:68-76. doi:10.1016/j.oraloncology.2017.09.009

13. Xu CW, Wang WX, Wu MJ, et al. Comparison of the c-MET gene amplification between primary tumor and metastatic lymph nodes in non-small cell lung cancer. Thorac Cancer. 2017;8:417-422. doi:10.1111/1759-7714.12455

14. Hass R, Jennek S, Yang Y, Friedrich K. c-Met expression and activity in urogenital cancers - novel aspects of signal transduction and medical implications. Cell Commun Signal. 2017;15(1):10. doi:10.1186/s12964-017-0165-2

15. Christensen JG, Schreck R, Burrows J, et al. A selective small molecule inhibitor of c-Met kinase inhibits c-Met-dependent phenotypes in vitro and exhibits cytoreductive antitumor activity in vivo. Cancer Res. 2003;63:7345-7355.

16. Ma PC, Schaefer E, Christensen JG, Salgia R. A selective small molecule c-MET inhibitor, PHA665752, cooperates with rapamycin. Clin Cancer Res. 2005;11(6):2312-2319. doi:10.1158/1078-0432. CCR-04-1708

17. Puri N, Khramtsov A, Ahmed S, et al. A selective small molecule inhibitor of c-Met, PHA665752, inhibits tumorigenicity and angiogenesis in mouse lung cancer xenografts. Cancer Res. 2007;67 (8):3529-3534. doi:10.1158/0008-5472.CAN-06-4416 
18. Yin B, Liu Z, Wang Y, et al. RON and c-Met facilitate metastasis through the ERK signaling pathway in prostate cancer cells. Oncol Rep. 2017;37(6):3209-3218. doi:10.3892/or.2017.5585

19. Zhang S, Song Q, Wang X, et al. Virtual screening guided design, synthesis and bioactivity study of Benzisoselenazolones (BISAs) on inhibition of c-Met and its downstream signalling pathways. Int J Mol Sci. 2019;20:2489.

20. Gill J, Ahluwalia MK, Geller D, Gorlick R. New targets and approaches in osteosarcoma. Pharmacol Ther. 2013;137(1):89-99. doi:10.1016/j.pharmthera.2012.09.003

21. Boromand N, Hasanzadeh M, ShahidSales S, et al. Clinical and prognostic value of the C-Met/HGF signaling pathway in cervical cancer. J Cell Physiol. 2018;233(6):4490-4496. doi:10.1002/jcp.26232

22. Awad MM, Oxnard GR, Jackman DM, et al. MET exon 14 mutations in non-small-cell lung cancer are associated with advanced age and stagedependent MET genomic amplification and c-Met overexpression. J Clin Oncol. 2016;34(7):721-730. doi:10.1200/JCO.2015.63.4600

23. Bahrami A, Shahidsales S, Khazaei M, et al. C-Met as a potential target for the treatment of gastrointestinal cancer: current status and future perspectives. J Cell Physiol. 2017;232(10):2657-2673. doi:10.1002/ jcp.25794

24. Fioramonti M, Fausti V, Pantano F, et al. Cabozantinib affects osteosarcoma growth through a direct effect on tumor cells and modifications in bone microenvironment. Sci Rep. 2018;8(1):4177. doi:10.1038/s41598-018-22469-5

25. Sampson ER, Martin BA, Morris AE, et al. The orally bioavailable met inhibitor PF-2341066 inhibits osteosarcoma growth and osteolysis/matrix production in a xenograft model. J Bone Miner Res. 2011;26(6):1283-1294. doi:10.1002/jbmr.336
26. Wang K, Zhuang Y, Liu C, Li Y. Inhibition of c-Met activation sensitizes osteosarcoma cells to cisplatin via suppression of the PI3K-Akt signaling. Arch Biochem Biophys. 2012;526(1):38-43. doi:10.1016/j.abb.2012.07.003

27. De Maria R, Miretti S, Iussich S, et al. met oncogene activation qualifies spontaneous canine osteosarcoma as a suitable pre-clinical model of human osteosarcoma. J Pathol. 2009;218:399-408. doi:10.1002/path.2549

28. Qian L, Su H, Wang G, Li B, Shen G, Gao Q. Anti-tumor activity of bufalin by inhibiting c-MET mediated MEK/ERK and PI3K/AKT signaling pathways in gallbladder cancer. $J$ Cancer. 2020;11 (11):3114-3123. doi:10.7150/jca.38393

29. El Bezawy R, De Cesare M, Pennati M, et al. Antitumor activity of miR-34a in peritoneal mesothelioma relies on c-MET and AXL inhibition: persistent activation of ERK and AKT signaling as a possible cytoprotective mechanism. J Hematol Oncol. 2017;10 (1):19. doi:10.1186/s13045-016-0387-6

30. Bonjardim CA. Viral exploitation of the MEK/ERK pathway - a tale of vaccinia virus and other viruses. Virology. 2017;507:267-275. doi:10.1016/j.virol.2016.12.011

31. Kyriakis JM, Avruch J. Mammalian MAPK signal transduction pathways activated by stress and inflammation: a 10-year update. Physiol Rev. 2012;92(2):689-737. doi:10.1152/physrev.00028.2011

32. Dhillon AS, Hagan S, Rath O, Kolch W. MAP kinase signalling pathways in cancer. Oncogene. 2007;26(22):3279-3290. doi:10. 1038/sj.onc. 1210421

\section{Publish your work in this journal}

OncoTargets and Therapy is an international, peer-reviewed, open access journal focusing on the pathological basis of all cancers, potential targets for therapy and treatment protocols employed to improve the management of cancer patients. The journal also focuses on the impact of management programs and new therapeutic agents and protocols on patient perspectives such as quality of life, adherence and satisfaction. The manuscript management system is completely online and includes a very quick and fair peer-review system, which is all easy to use. Visit http://www.dovepress.com/ testimonials.php to read real quotes from published authors 